\title{
Feminizing adrenocortical carcinoma in a postmenopausal woman
}

\author{
B. BARCELO \\ M.D. \\ J. ARDAIZ \\ M.D. \\ A. Colas \\ M.D.
}

\author{
J. Abascal \\ M.D. \\ P. GIL \\ M.D. \\ J. MENENDEZ
M.D.
}

\section{J. L. INCHAUSTI \\ M.D.}

Endocrine Unit, Department of Surgery and Department of Pathology, Clinica Puerta de Hierro, Autonomous University, Madrid, Spain

\section{Summary}

The successful surgical removal of a feminizing adrenal tumour in a postmenopausal woman is described. Most of these tumours are malignant and the pathological findings and the biological behaviour of the tumour frequently do not correlate, so that a careful follow-up is necessary. In the presence of vaginal bleeding in a postmenopausal woman endometrial carcinoma should be considered. If this has been ruled out and if oestrogens are elevated with low plasma gonadotrophins, a feminizing ovarian or adrenal tumour should be considered.

\section{Introduction}

Feminizing adrenocortical tumours are rare, In a review of the world literature, Gabrilove et al. (1970) recorded 62 such cases in males and 5 cases in females. Since that date, 3 more cases affecting females have been published (Banich and Fox, 1970; Mathur et al., 1973; Golder et al., 1975).

In the adult female, the clinical diagnosis of these tumours is difficult, probably because of the problem of recognizing the effects of extra-ovarian oestrogens.

In postmenopausal females complaining of vaginal bleeding, if endometrial carcinoma and feminizing ovarian tumour have been excluded with certainty, an adrenal tumour should be considered.

A case is now reported of a feminizing adrenal tumour diagnosed pre-operatively in a postmenopausal woman.

\section{Case report}

The patient was first treated for a toxic thyroic adenoma when she was 63 years old. At that time she was normotensive and had a normal intravenous urogram and ECG.

She presented again at the age of 69 years with a complaint of 2 months' vaginal bleeding. Her menopause had occurred at the age of 51 years.

On examination the breasts were atrophic, but the uterus was enlarged. The ovaries were normal and there were no abdominal masses. Blood pressure at this time was $130 / 90 \mathrm{mmHg}$.

The ESR was elevated at $72 \mathrm{~mm} / \mathrm{hr}$. Urine analysis, blood count, haematocrit, urea and electrolytes, creatinine, liver function tests and serum calcium were normal.

Vaginal cytology revealed marked oestrogenic activity. Cervical dilatation and uterine curettage yielded endometrium showing glandular hyperplasia with no evidence of malignancy. Hormonal studies are depicted in Fig. 1. The total plasma oestrogens and plasma testosterone levels were high. Plasma gonadotrophin levels were very low. FSH and LH were measured by radioimmunoassay and plasma testosterone and total plasma oestrogens by methods described elsewhere (Edquist and Johansson, 1972; Forest, Cathiard and Bertrand, 1973).

Plain chest and abdominal X-ray films were normal. Nephrotomography, however, showed the existence of a left adrenal mass.

A diagnosis of feminizing adrenal tumour was 

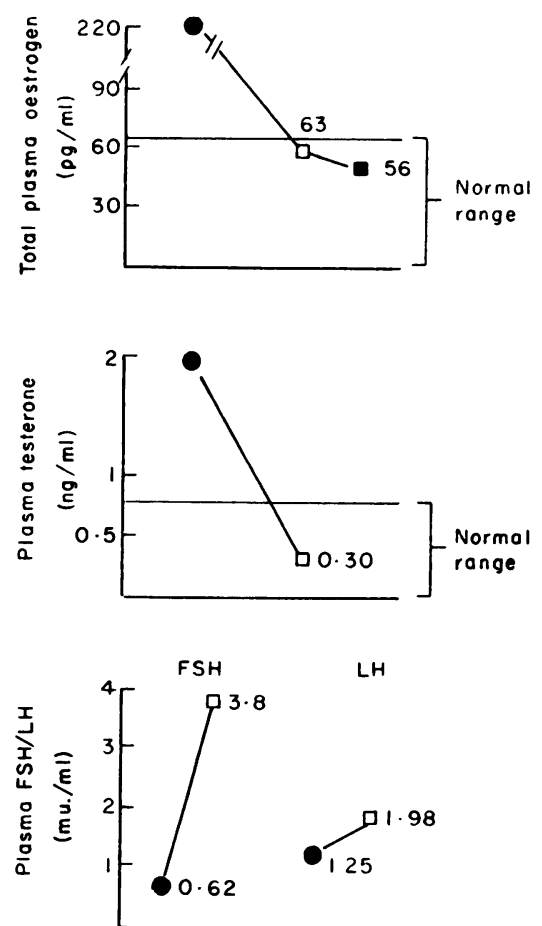

FIG. 1. Hormonal determinations before and after operation. Plasma follicle-stimulating hormone (FSH) and luteinizing hormone (LH) postmenopausal normal values: <40 mu./ml.

- Pre-operative values; $\square$ Postoperative values (7 days after operation); values one year after operation.

made and laparotomy was performed. A left adrenal tumour measuring $10 \times 7 \times 5 \mathrm{~cm}$ and weighing $450 \mathrm{~g}$ was removed. Histologically there were cytological atypia, necrosis and capsular invasion, suggestive of adrenocortical carcinoma (Fig. 3).

The postoperative convalescence was uneventful. Further determinations of plasma testosterone and total oestrogens demonstrated decreasing levels (Fig. 2). The ESR returned to normal. Two years after surgery the patient remains asymptomatic and well.

\section{Discussion}

Most feminizing adrenogenital syndromes reported to date occurred in males, and most of them have been produced by tumours (Gabrilove et al., 1965, 1970, 1973; Howard, Takahashi and Hayles, 1977). The world literature yields only 8 cases of feminizing adrenal tumours in females, only 3 of them in postmenopausal women (Mathur et al., 1973; Golder et al., 1975; Monsaingeon, Camus and Ennuyer, 1963). In these cases, vaginal bleeding was the main manifestation of the tumour. In one case

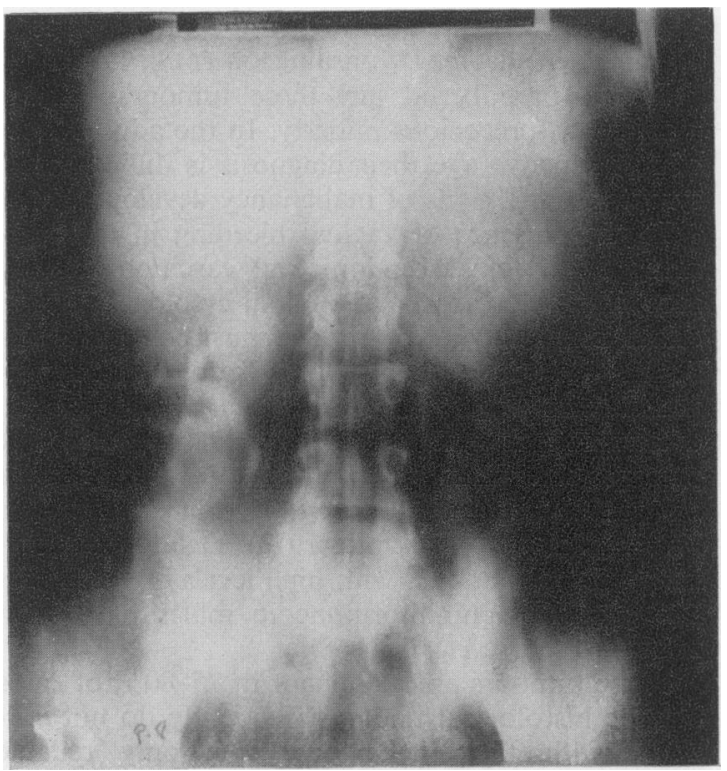

Fig. 2. Nephrotomography (Plane 8). A peripherally calcified left adrenal mass may be seen. This mass rotated and displaced the left kidney downward.

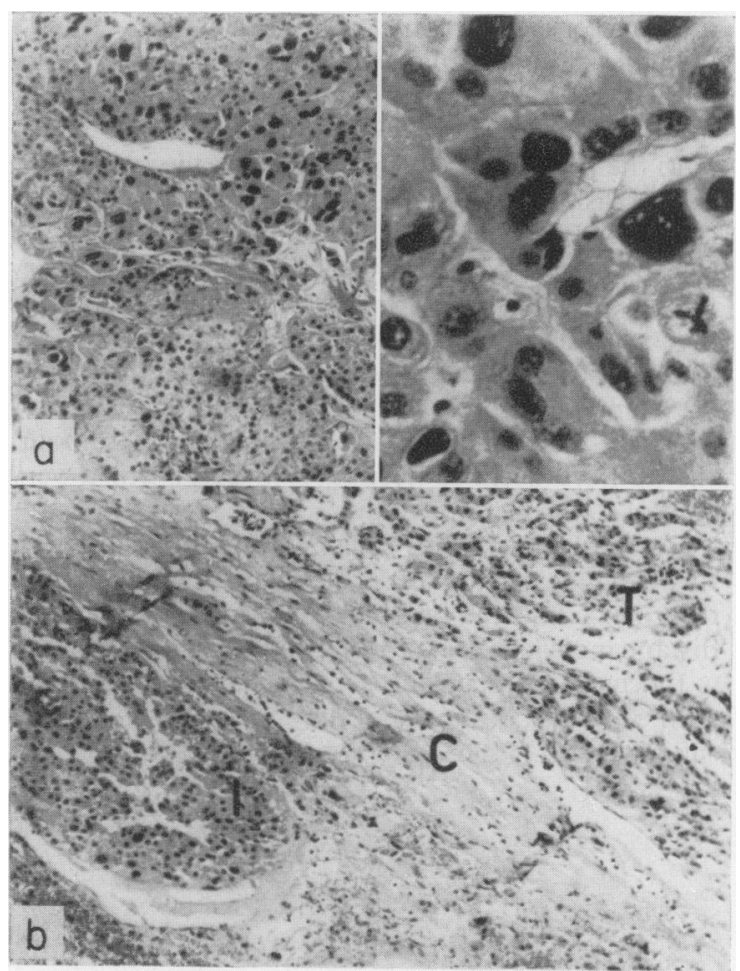

FIG. 3. (a) Right: Patent nuclear polymorphism in the tumoral structure. Left: Multinucleated cells with atypical mitosis.

(b) Capsular invasion: A tumoral islet (I) may be seen outside of the capsule's (c) tumour $(T)$. 
there was associated evidence of hirsutism and Cushing's syndrome (Monsaingeon et al., 1963).

In the prepubertal girl these tumours become manifest as precocious puberty. In the adult female of reproductive age their diagnosis is difficult until symptoms and signs of malignancy develop.

In the presence of vaginal bleeding in the postmenopausal female endometrial carcinoma is the most likely diagnosis and vaginal cytology, cervical dilatation and uterine curettage must be carried out. When this procedure yields an endometrial hyperplasia with high oestrogenic activity, hormonal determinations must be carried out to exclude the presence of feminizing ovarian or adrenal tumours or a gonadotrophin-producing tumour (Bjersing, Frankendal and Angstrom, 1973). Details of feminizing adrenal tumours with high levels of chorioniclike gonadotrophin hormone in males have been published (Rose et al., 1968).

These tumours are malignant in $75-80 \%$ of cases but the histological findings frequently do not correlate with their behaviour. The only reliable findings of malignancy are metastases. Fifty per cent. of patients with malignant tumours died within 18 months after the onset of symptoms and $80 \%$ within 3 years. A few patients survived for as long as 6 years after surgery (Solomon et al., 1968).

Feminizing adrenal tumours usually produce oestriol and oestrone rather than the biologically more active oestradiol (Greenwood, 1974).

In the present patient, plasma testosterone and the total plasma oestrogens, returned to normal after surgery. Plasma gonadotrophins have increased slightly soon after surgery. Two years after surgery the patient is asymptomatic and no evidence of metastasis is present.

Owing to the size and weight of the tumour in this case and the presence of multiple atypias and capsular invasion suggesting a malignant tumour, the authors deem it necessary to carry out a very careful follow-up procedure.

Postoperative recurrences will become manifest through renewed feminization, increase of the plasma oestrogens and the presence of local recurrence and distant metastasis (liver, lung, bone, etc.).

In cases of recurrences or metastasis, treatment with $o, p^{\prime}$-DDD (mitotane) may be of benefit (Monsaingeon et al., 1963; Solomon et al., 1968).

\section{Acknowledgments}

We are grateful to the Department of Photography of the University of Newcastle upon Tyne and to Miss J. Kehoe $\varrho$ for secretarial assistance.

\section{References}

BANICH, F.E. \& Fox, P.F. (1970) Feminizing tumor of the adrenal gland in a five-year-old female. Proceedings of the Institute of Medicine of Chicago, 28, 82.

Bjersing, L., Frankendal, B. \& Angstrom, T. (1973) 光 Studies on a feminizing ovarian mesenchymoma (granulosa cell tumor). Aspiration biopsy cytology, histology and . ultrastructure. Cancer, 32, 1360.

EdQuisT, L.E. \& JohaNSSON, E. (1972) Radioimmunoassay of oestrone and oestradiol in human and bovine peripheral plasma. Acta endocrinologica. Copenhagen, 71, 716.

Forest, M.G., CAThiard, A.M. \& Bertrand, J.A. (1973) Total and unbound testosterone levels in the newborn and in normal and hypogonadal children: Use of a sensitive radioimmunoassay for testosterone. Journal of Clinical Endocrinology and Metabolism, 36, 1132.

Gabrilove, J.L., Nicolis, G.L. \& Hausknecht, R.U. et al. (1970) Feminizing adrenocortical carcinoma in a man. Cancer, 25, 153.

Gabrilove, J.L., Nicolis, G.L. \& Sohval, A.R. (1973) Non-tumorous feminizing adrenogenital syndrome in the male subject. Journal of Urology, 110, 710.

Gabrilove, J.L., Sharma, D.C. \& Wotiz, H.H. et al. (1965) Feminizing adrenocortical tumors in the male. A review of 52 cases including a case report. Medicine. Baltimore Colombo or Detroit? 44, 37.

Golder, M.P., Millington, D.S. \& Cowley, T.H. et dK (1975) Hormonal control of steroid synthesis by a feminizing adrenal tumour. Journal of Endocrinology, 67, 17.

Howard, C.P., Takahashi, M. \& Hayles, A.B. (1977) Feminizing adrenal adenoma in a boy. Case report and literature review. Proceedings. Mayo Clinic, 52, 354.

GreENwOOD, R.H. (1974) Selective feminization due to an adrenal carcinoma. Proceedings of the Royal Society of Medicine, 67, 671.

Mathur, R.S., Williamson, H.O., Moody, L.O. \& DiczFALUSY, E. (1973) In vitro sterol and steroid biogenesis by a feminizing adrenocortical carcinoma. Acta endocrinologica. Copenhagen, 73, 518.

Monsaingeon, A., Camus, J.L. \& Ennuyer, A. (1963) Feminizing adrenocortical tumour in a menopausal woman, comparison of the endocrine effects of surgical action and treatment of Op DDD. Presse Médicale, 71, 2087.

Rose, L.I., Williams, G.H., Jagger, P.I. \& Lauler, D.P. (1968) Feminizing tumor of the adrenal gland with positive 'Chorionic-like' gonadotrophin test. Journal of Clinical Endocrinology and Metabolism, 28, 903.

Solomon, S.S., Swersie, S.P., PAulsen, C.A. \& Biglieri, E.G. (1968) Feminizing adrenocortical carcinoma with hypertension. Journal of Clinical Endocrinology and Metabolism, 28, 608. 